\title{
SIGNIFICANCE OF ADENOSINE DEAMINASE SERUM CONCENTRATIONS IN THE DIAGNOSIS OF EXTRA-PULMONARY TUBERCULOSIS
}

\author{
Stevanovic G., Pelemis M., Pavlovic M., Lavadinovic L., Dakic Z., Milosevic I., \\ Milosevic B. \\ Institute for infectious and tropical diseases, \\ Clinical center of Serbia, Belgrade, Serbia
}

\begin{abstract}
Extra pulmonary tuberculosis (EPTB) is a growing problem worldwide. Due to the nature of the disease, the diversity of clinical pictures as well as its minor epidemiological importance, the diagnosis is difficult and often late.

In addition to standard TB diagnostic techniques use of new biochemical (surrogate markers) are increased.

With this work we wanted to examine the usefulness of serum adenosine deaminase levels as a diagnostic parameter for EPTB.

The work included 116 patients with fever of unknown origin in which tuberculosis or infectious mononucleosis was not proven and 51 person who had proven EPTB. Correlated adenosine deaminase levels between these two groups we obtained significantly higher values in patients with EPTB. The calculated sensitivity was 0.56 , specificity 0.89 , positive predictive value 0.80 and negative predictive value 0.72 . Certain reducing of the values observed during anti TB therapy.

In previous studies the diagnostic importance of adenosine deaminase in the diagnosis of tuberculosis serosityes was demonstrated. The significance of serum levels in diagnosis is rarely evaluated during EPTB. Our findings are similar to the results of authors who have conducted such testing in the pediatric population.

Increased concentrations of serum adenosine deaminase have shown the potential of usable screening test and can be used as an indicative EPTB parameter. To fully assess its diagnostic significance require future clinical research.
\end{abstract}

Key words: fever of unknown origin, diagnostic, biochemical markers, tuberculosis

\section{INTRODUCTION}

Tuberculosis is an infection with human strains of Mycobacterium tuberculosis mycobacterium with the occurrence of the characteristic immune response. The most common form of the disease, which is essential for the spread of TB, is pulmonary. Tuberculosis can affect any organ in the body. Term extra- pulmonary tuberculosis (EPTB) is referred to isolated TB at any site in the body outside the lungs.

Until the appearance of human immunodeficiency virus (HIV) incidence of tuberculosis in the world has been declining, but the eighties of the twentieth century, tuberculosis re-imposed as a disease of growing interest (1). In the period 1985-1992 year, there was an increased incidence of tuberculosis in both developing and developed countries including the United States and that trend continues (2). It is estimated that the around the world; two billion people are infected with tuberculosis, of which about 8 million develop active TB annually, and about 2 million die (1). Tuberculosis, on the bases o of the report of the Center for Disease Control, Atlanta / CDC / from 2005 was considered be leading cause of death among infectious diseases with an estimated number of 3 million deaths annually (3).

Particularly concerned by evidence that the incidence of tuberculosis and EPTB growing everywhere in the world and in HIV-negative population too $(1,3)$.

During the late 1990, TB incidence levelled of after a long period of decreasing trend during the preceding several decades (4). In particular, the increasing incidence in elderly patients. (5)

The incidence of disease, according to data of the Institute of Public Health in 2009, was 22.27 per 100,000 population. (6) There in no data on the incidence of extrapulmonary tuberculosis.

Among patients with fever of unknown origin (FOU), the number of cases of extrapulmonary tuberculosis as an etiological factor were incrised.(7)

As TB can affect virtually any organ or organ system in the body, clinical EPTB varieties are numerous, which makes the diagnosis difficult. Adenosine deaminase levels determination is used as one of the tests to prove serosal tuberculosis.

There is also some elevation of serum concentrations that could be used as a screening test (8). 


\section{OBJECTIVES}

To compare the serum concentrations of adenosine deaminase in patients with EPTB and patients who are examined because of fever of unknown origin. To assess the existence of any predictive value of adenosine deaminase serum concentration to outcome.

\section{MATERIALS AND METHODS}

The subjects were patients of the Department of clinical pharmacotherapy Institute for Infectious and Tropical Diseases, Clinical Center of Serbia, who were hospitalized for investigation for fever of unknown origin. During the period January 2007 to May 2010, in 167 patients the adenosine deaminase levels was measured during diagnostic FOU. In 51 of the patient tuberculosis infection was proved by some of the methods used (Group I), while 116 had not had tuberculosis (Group II). All patients were HIV negative.

In addition to anamnesis, physical examinations were done and all the diagnostic procedures required for diagnosis of FUO. In addition to standard examinations (Xray of the lungs, abdomen echo), and standard biochemical tests, depending on the presentation of illness intravenous pielonephrography (IVP), abdomen, chest or pelvic CT scan, echocardiography, computed tomography (CT) and nuclear magnetic resonance (NMR) of the spine were done. The equipment and services of the Radiology Service of Clinical Center of Serbia were used. The histological processing of tissues of clinical interest (biopsy of the liver, LGL, peritoneum, small bowel and adnexa) were also conducted. Histological processing of tissue samples were performed at the Institute of Pathology, University of Belgrade.

The level of adenosine deaminase was determined by enzymatic method, test "ADA tiazyme labs" on device "Olympus AU 680"; from blood samples collected in a test tube without additives. The level of reference values specified by the laboratory was $0-24 \mathrm{U} / \mathrm{L}$. We excluded from the study with patients with proven infectious mononucleosis due to the specific pathogenesis of the disease where high levels of adenosine deaminase are expected. In all patients the concentration of adenosine deaminase was determined in the initial diagnostic protocol. Patients who were proven specific infections, control values were observed at 1,2,6 and 12 months after treatment start. Patients with proven tuberculosis infection were treated for two months with four drugs (Rifampin, Isoniazid, Pyirazinamide, Ethambutol), and then another four months with two drugs (Rifampin, Isoniazid).

Due to the heterogeneity of data, although the observed parameters were continuous, we used nonparametric tests $\left(\chi^{2}\right.$ test). The study was approved by the Clinical Center of Serbia Ethics Committee.

\section{RESULTS}

Adenosine deaminase was determined in a total of 167 patients. In both groups of men and women was approximately equal. In group I there were 24 men and 27 women. While in group II were 57 men and 59 women. Most patients had between 40 and 60 years of age. The group I eight patients $(15,6 \%)$ had a chronic illness or current use of corticosteroids, and $14(27,5 \%)$ had data of the presence of TB in the family or in personal history. In group II, 28 patients $(24,1 \%)$ had chronic disease, while only $11(9,5 \%)$ had data on TB in the surrounding.

Causes of FUO are shown in Graph 1.

Most frequently, EPTB was localized in the urogenital tract and lymph nodes, other localizations have been less. (Graph 2)

Using a group of patients with fever of unknown origin (without proven specific infection or infectious mononucleosis) as a control and its comparison with the group of EPTB patients, we obtained a highly statistical significant incidence difference $(\mathrm{p}<0.001)$ of elevated adenosine deaminase concentrations. (Table 1)

From these data the calculated sensitivity was 0.56 , specificity 0.89 , positive predictive value 0.80 and negative predictive value 0.72 . Also, average concentrations of adenosine deaminase show a statistically significant difference (decline in value) as a function of time after treatment began. (Table 2).

Initial concentration of adenosine deaminase did not show statistically significant predictive value in the success of treatment.

\section{DISCUSSION}

Definitive diagnosis of tuberculosis includes a demonstration of the presence of $\mathrm{M}$. tuberculosis by microbiological, cytological or histopathological methods. Classical methods of TB diagnostics have significant limitations for diagnosis of EPTB. Cultivation is to long, while in these patients often requires rapid diagnosis. Material for PCR diagnosis is often not possible to take (except cerebro spinal fluid and urine), and histopathological confirmation requires biopsies, which are invasive.The most reliable diagnostic criteria, is still confirm the presence of bacilli in the patient material by cultivation $(9,10,11)$. In some forms EPTB material can be take for cultivation (renal, meningeal, pleural, and pericardial). In these cases, unfortunately, successful cultivation is very variable, and the pleural fluid ranged from $12-70 \%(12,13,14)$, the pericardial fluid performance is $25-60 \%(15,16,17)$, and cerebrospinal fluid is ranges from $40-80 \%(18,19,20)$.

Because of these problems in exact diagnosis of tuberculosis numerous additional tests are in use with the intention to facilitate the diagnosis.

In the recent use are among others, tests who determine the biological (biochemical) markers of 
tuberculosis infection, such as levels of adenosine deaminase concentration (ADA) or the level of interferon gamma. Adenosine deaminase (ADA) is an enzyme in the purine salvage pathway that catalyzes the conversion of adenosine and deoxyadenosine to inosine and deoxyinosine with the release of ammonia. This is an important enzyme in T-lymphocytes where it is in 10 time's higher concentration than in erythrocytes. Its activity increased during the reproduction and response to antigenic stimulation of lymphocytes (21). Therefore, its increased concentration may be found in all fluids occurred in the zones of tuberculosis serositis $(8,22)$, which is used in diagnostic.

So far in the literature and practice measurement of the concentration of adenosine deaminase in effusions was proved as tuberculoses etiology marker of great importance.

Piras et al were first to report high ADA in tubercular pleural effusion (23). Meta-analysis of studies conducted between 1966 and 1999 concluded that the test performance was reasonably good (24) (sensitivity range $47.1-100 \%$, and specificity $0-100 \%$ ) in diagnosing tuberculosis etiology in pleural effusion. In 2007, a systematic review of ADA by the NGS Health Technology Assessment Programme concluded that there is no evidence to support the use of ADA tests for the diagnosis of pulmonary TB. However, there is considerable evidence to support their use in pleural fluid samples for diagnosis of pleural TB, where sensitivity was very high, and to a slightly lesser extent for TB meningitis. In both pleural TB and TB meningitis, ADA tests had higher sensitivity than any other tests (25).

Also in Serbia, Zaric and colleagues have shown the importance of $\mathrm{ADA}$ in the differential diagnosis of pleural effusions. (26)

Other researchers have also observed the usefulness of ADA activity in the diagnosis of tuberculosis disease (27, 28).

Other causes of increase in ADA activity include bacterial infections, rheumatic disease and lymphoproliferative disorders. The article reviews of Gupta $\mathrm{BK}$ et al. ADA estimation as an effective diagnostic criterion for tuberculous and non-tuberculous disease in pleural, ascitic, synovial fluids and CSF. (8)

In extra-pulmonary disease, overall sensitivity in this study was found to be $94.29 \%$, specificity $92.16 \%$, positive predictive value $89.00 \%$ and negative predictive value $95.92 \%$; and in pulmonary disease, sensitivity was found to be $92.80 \%$, specificity $90.00 \%$, positive predictive value $92.86 \%$ and negative predictive value $90.00 \%$.

From the above it is evident that determination of this enzyme was reliable and useful test for the detection of tuberculosis infection in serous spaces (pleural, peritoneal, synovial space, cerebrospinal fluid) $(8,26,29)$. Srinivasa et al.were found elevated serum adenosine deaminase levels in patients with pulmonary tuberculosis.(30) There is no data in the literature that someone on territory of Serbia was measure the level of adenosine deaminase in serum in order to diagnose EPTB. In our sample the average value of its concentration was elevated. Similar data were presented by Mishra and colleagues in childrens population, where in addition to lung tuberculosis they had patients with miliary and extrapulmonary localization. (31)

In our sample standard deviation was high, and because of that we had a relatively small resulting sensitivity, while specificity was satisfactory. Positive predictive value of this test is high and this gives him a place as a widely usable screening test in the diagnosis of EPTB. Our results, we could not compare with the data from the literature since we did not find data on the sensitivity, specificity or the positive or negative predictive value of serum adenosine deaminase.

As the localization of TB infection were diverse, with a relatively small number of individual cases, we could not determine whether a higher value of adenosine deaminase corelatied with particulare localization.

Adenosine deaminase higher levels were found in patients with rheumatoid arthritis and other autoimune diseases, which agree with the findings of other authors. (32)

\section{CONCLUSION}

Increased concentrations of serum adenosine deaminase have shown the potential of usable screening test. To definitively determine the reference values $\dagger$ for serum adenosine deaminase and to fully assess its diagnostic significance require significantly larger sample. For now, the serum concentration of adenosine deaminase can be used as an indicative EPTB parameter, in the context of which its findings should be interpreted as part of a complete clinical presentation of disease.

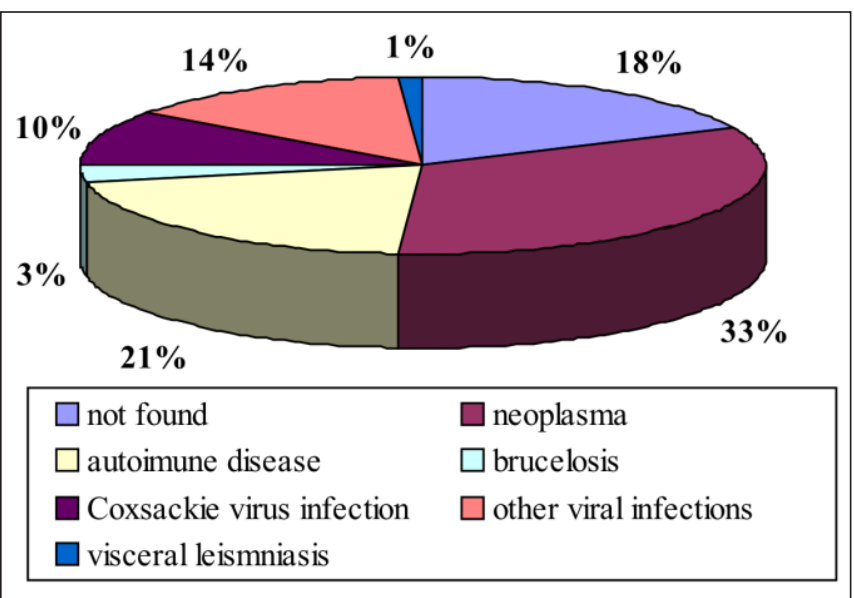

Graph. 1. Causes of FUO 


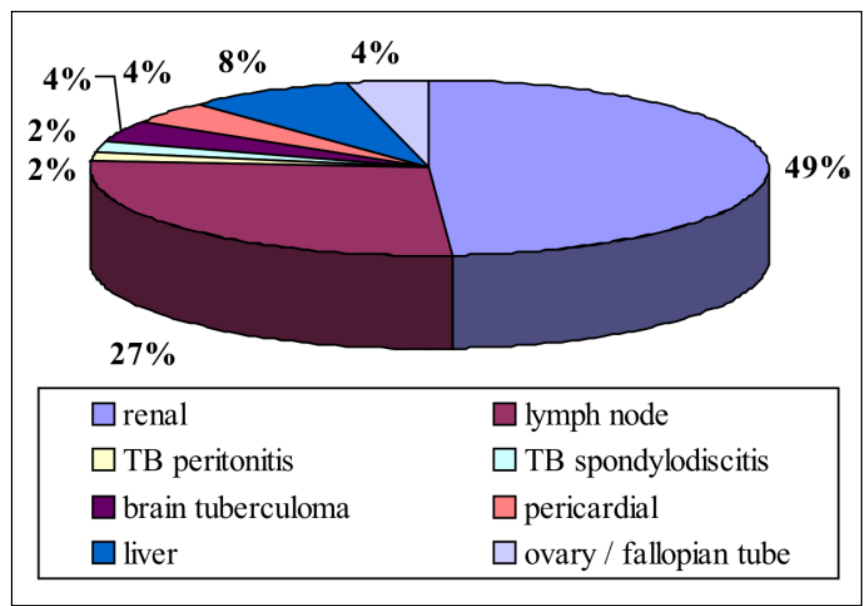

Graph. 2. Localisation of EPTB

Table 1. The frequency of elevated values for adenosine deaminase in patients with fevers, for that is proven EPTB, and patients without TB

\begin{tabular}{|l|l|c|c|c|}
\hline \multicolumn{2}{|c|}{} & \multicolumn{2}{|c|}{ Adenosine deaminasis } & \multirow{2}{*}{ Total } \\
\cline { 3 - 5 } \multicolumn{2}{|c|}{ Specific infection } & elevated & normal & 51 \\
\cline { 2 - 5 } & was proven & 41 & 10 & 116 \\
\hline & has not been proven & 32 & 84 & 167 \\
\hline
\end{tabular}

Table 2. Average concentration of adenosine deaminase in the beginning, after one, two, six and twelve months after commencement of treatment in 51 patients with EPTB

\begin{tabular}{|l|c|c|c|c|c|}
\hline Months of starting treatment & 0 & I & II & VI & XII \\
\hline Mean concentration \pm SD & $31 \pm 11$ & $20 \pm 9$ & $10 \pm 3$ & $7 \pm 3$ & $6 \pm 2$ \\
\hline
\end{tabular}

\section{REFERENCES:}

1. Dye C, Scheele S, Dolin P, Pathania V, Raviglione MC. Consensus statement. Global burden of tuberculosis: estimated incidence, prevalence and mortality by country. WHO Global Surveillance and Monitoring Project. JAMA. 1999 Aug 18;282(7):677-86. [PubMed][ doi: 10.1001/ jama.282.7.677]

2. Golden MP, Vikram HR. Extrapulmonary tuberculosis: An overview. Am Fam Physician. 2005 Nov 1;72(9) 1761-8 [PubMed]

3. Centers for disease control and prevention (CDC). Trends in tuberculosisUnited States, 1998-2003. MMWR Morb Mortal Wkly Rep. 2004 Mar 19;53(10): 209-14. Erratum in MMWR Morb Mortal Wkly Rep. 2004 Mar 26;53(11):246. [PubMed]

4. Gledovic Z, Vlajinac H, Pekmezovic
T, Grujicic-Sipetic S, Grgurevic A, Pesut D. Burden of tuberculosis in Serbia. Am J Infect Control. 2006 Dec;34(10):676-9 [PubMed]

5. Pesut DP, Gledovic ZB, Grgurevic AD, Nagorni-Obradovic LJM and Adzic TN. Tuberculosis Incidence in Elderly in Serbia: Key Trends in Socioeconomic Transition. Croat Med J. 2008 Dec; 49(6): 807-812 [PubMed] [doi:10.3325/cmj. 2008.49.807 ]

6. http://www.batut.org.rs/download/ health_indicators_rs.html

7. Pelemis M, Stevanovic G, Pavlovic M, Nikolic S, Lavadinovic L, Milosevic B, Poluga J, Milosevic I, Nikolic J, Divac N, Prostran M. Importance of extrapulmonary tuberculosis during evaluation of patients with fever of unknown origin. Oral presentation; 26th International congress of chemotherapy and infection, june, 2009, Toronto, Canada. (Pulication in International Journal of Antimicrobial AgentsVol. 34, Suppl2 (July 2009) O45, S16.)

8. Gupta BK, Bharat V, Bandyopadhyay D. Sensitivity, specificity, negative and positive predictive values of adenosine deaminase in patients of tubercular and nontubercular serosal effusion in India. J Clin Med Res. 2010 May 19;2(3):121-6 [PubMed]

9. Pelemis M, Pavlovic M, Lavadinovic L, Stevanovic G, Milosevic B, Sasic M, Canic T. Extrapulmonary tuberculosis problem in differential diagnosis in patients with fever of unknown origin. Journal of Antimicrobial Chemotherapy, 21st International Congress of Chemotherapy, Birmingham, UK, 4-7 july, 1999, Supplement A to Vol 44; 121 
10. Agadi S. Diagnosis of tuberculosis. Lancet 2003 Jun 14;361(9374):2082; author reply 2082-3. [PubMed]

11. Radford AJ, Rothel JS. Diagnosis of tuberculosis. Lancet 2003 Jun 14;361(9374):2083 [PubMed]

12. Valdes L, Pose A, San Jose E, Martinez Vazquez JM. Tuberculous pleural effusions. Eur J Intern Med. 2003 Mar; 14(2): 77-88. [PubMed]

13. Light RW. Management of pleural effusions. J Formos Med Assoc. 2000 Jul; 99(7):523-31. [PubMed]

14. Ferrer J. Pleural tuberculosis. Eur Respir J. 1997 Apr;10(4):942-7 [PubMed]

15. Fowler NO. Tuberculous pericarditis. JAMA. 1991 Jul 3;266(1):99-103 [PubMed]

16. Trautner BW, Darouiche RO. Tuberculous pericarditis: optimal diagnosis and management. Clin Infect Dis. 2001 Oct 1;33(7):954-61. Epub 2001 Aug 22. [PubMed] [doi: 10.1086/322621]

17. Strang JIG, Kakaza HHS, Gibson DG, Girling DJ, Nunn AJ, Fox W. Controlled trial of prednisolone as adjuvant in treatment of tuberculous constrictive pericarditis in Transkei. Lancet. 1987 Dec 19; 2(8573):1418-22 [PubMed]

18. Thwaites GE, Chau TT, Stepniewska K, Phu NH, Chuong LV, Sinh DX, et al. Diagnosis of adult tuberculous meningitis by use of clinical and laboratory features. Lancet. 2002 Oct 26; 360 (9342): 1287-92. [PubMed] doi: 10.1016/S01406736(02)11318-3

19. Nikolic S. Tuberkulozni meningitis u: Infektivne bolesti udzbenik za studente medicine, Medicinski fakultet Univerziteta u Beogradu, CIBID, 2007: 89-93 (in Serbian) 20. Ibrarullah M, Mohan A, Sarkari A, Srinivas M, Mishra A, Sundar TS. Abdominal tuberculosis: diagnosis by laparoscopy and colonoscopy. Trop Gastroenterol. 2002 Jul-Sep;23(3):150-3 [PubMed]

21. Sharma SK, Suresh V, Mohan A, Kaur P, Saha P, Kumar A, et al. A prospective study of sensitivity and specificity of adenosine deaminase estimation in the diagnosis of tuberculosis pleural effusion. Indian J Chest Dis Allied Sci. 2001 Jul-Sep; 43(3):149-55. [PubMed]

22. Mathur PC, Tiwari KK, Sushima T, Tiwari D. Diagnostic value of adenosine deaminase (ADA) activity in tubercular serositis. Indian J Tuberc 2006; 53: 92-95

23. Piras MA, Gakis C, Budroni M, Andreoni G. Adenosine deaminase activity in pleural effusions: an aid to differential diagnosis. Br Med J 1978 Dec 23-30;2 (6154):1751-1752 [PubMed] [doi: 10.1136/ bmj.2.6154.1751-a ]

24. Goto M, Noguchi Y, Koyama H, Hira K, Shimbo T, Fukui T. Diagnostic value of adenosine deaminase in tuberculous pleural effusion: a meta-analysis. Ann Clin Biochem. 2003 Jul; 40(Pt 4):374-381 [PubMed] [doi: 10.1258/000456303766477 011]

25. Dinnes J, Deeks J, Kunst H, Gibson A, Cummins E, Waugh $\mathrm{N}$, et al. A systematic review of rapid diagnostic tests for the detection of tuberculosis infection. Health Technol Assess. 2007 Jan;11(3):1196. [PubMed]
26. Zaric B, Kuruc V, markovic M, Canak V, Milovancev A, Jovanovic S, Sarcev T. Diagnostic tools for tuberculous pleurisy: Where is the place of Adenosine deaminase (ADA?) Chest 2007; 132 (4): 463s

27. Prasad R, Kumar A, Khanna BK. CSF-ADA for the diagnosis of TBM. Ind Jour Tub., 1991;38:99-102

28. Mishra OP, Loiwal V, Ali Z, Nath G, Chandra L, Das BK. Cerebrospinal fluid adenosine deaminase activity and $\mathrm{C}$-reactive protein in tuberculous and partially treated bacterial meningitis. Indian Pediatr. 1995 Aug; 32(8):886-889 [PubMed]

29. Blake J, Berman P. The use of adenosine demaninase assays in the diagnosis of tuberculosis. S Afr Med J. 1982 Jul 3;62(1):19-21. [PubMed]

30. Srinivasa RK, Kumar HA, Rudresh BM, Srinivas T, Bhat KH. A comparative study and evaluation of serum adenosine deaminase activity in the diagnosis of pulmonary tuberculosis. Biomed Res. 2010 (2): 189-94

31. Mishra OP, Yusaf S, Ali Z, Nath G, Das BK. Brief report. Adenosine deaminase activity and lysozyme levels in children with tuberculosis.B J Trop Pediatr. 2000 Jun;46(3):175-178. [PubMed] [doi: 10.1093/tropej/46.3.175]

32. Hitoglou S, Hatzistilianou M, Gougoustamou D, Athanassiadou F, Kotsis A and Catriu D. Adenosine deaminase activity and its isoenzyme pattern in patients with juvenile rheumatoid arthritis and systemic lupus erythematosus, Clin Rheumatol. 2001 20(6):411-416. [PubMed] [doi: 10.1007/s100670170005 ]

\section{Corresponding author:}

Dr. Goran Stevanovic, M.D., specialist for infectious diseases, Institute for infectious and tropical diseases, Clinical center of Serbia, Bulevar Oslobodjenja 16, 11000 Belgrade, Serbia

E-mail: goran_drste@yahoo.com 